\title{
O TRAJETO EDUCACIONAL DOS OBLATOS DE SÃO JOSÉ: REFLEXÕES PARA UMA FORMAÇÃO HUMANA VIRTUOSA
}

\author{
The educational path of the sao josé oblates: reflections for a virtual human formation
}

\author{
Jose Alves de Melo Neto ${ }^{1}$
}

\begin{abstract}
RESUMO: Esta pesquisa bibliográfica, com abordagem qualitativa, visa compreender a proposta educativa dos Oblatos de São José, uma congregação religiosa fundada pelo bispo italiano São José Marello (1844-1895) A princípio está organizada a partir de uma educação humanista estabelecida no século XVIII, resultante da vivência pastoral e social do sacerdote fundador. Tendo como modelo José de Nazaré, pai e educador de Jesus, José Marello propõe para seus oblatos a "educação da mente e do coração", como proposta educativa da integralidade da pessoa humana. Educar a mente e o coração é, talvez, um dos pressupostos máximos do jeito de fazer educação para São José Marello. Esse desejo, fortemente presente nos seus esforços, motivou a realização desta pesquisa, no intuito de entender como estes pressupostos se revelam nas atividades pastorais e no "jeito de educar", nas instituições educacionais oblatas brasileiras. O percurso da pesquisa permitiu verificar a atualidade do carisma de São José Marello. Passado mais de um século, e sem deixar de considerar as diferenças especialmente culturais e sociais deste novo tempo, entende-se que os seus ensinamentos fundamentais, ou seja, a sua essência, continua viva, mesmo que em nova forma, própria dos novos processos e técnicas presentes no ambiente educacional.
\end{abstract}

PALAVRAS-CHAVE: Educação; Pastoral Escolar; Educação Católica; Oblatos de São José.

ABSTRACT: This bibliographical research, with a qualitative approach, aims to understand the educational proposal of the Oblates of St. Joseph, a religious congregation founded by the Italian bishop St. Joseph Marello (1844-1895). At first it is organized from a humanist education established in the eighteenth century, resulting from of the pastoral and social experience of the founding priest. Having as model José de Nazaré, father and educator of Jesus, José Marello proposes to his oblates the "education of the mind and heart", as an educational proposal of the integrality of the human person. Educating the mind and heart is perhaps one of the highest assumptions of how to educate St. Joseph Marello. This desire, strongly present in his efforts, motivated this research, in order to understand how these assumptions are revealed in pastoral activities and in the "way of educating", in Brazilian oblate educational institutions. The course of the research allowed us to verify the current charism of St. Joseph Marello. More than a century has passed, and without considering the especially cultural and social differences of this new era, it is understood that its fundamental teachings, ie their essence, remain alive, even in a new form, characteristic of the new processes. and techniques present in the educational environment.

KEYWORDS: Education; Pastoral School; Catholic Education; Oblates of Saint Joseph.

\footnotetext{
${ }^{1}$ Possui graduação em Teologia pela Pontifícia Universidade Católica de São Paulo (2013), graduação em Filosofia pela Faculdade Padre João Bagozzi (2008), especialização em Pastoral Juvenil pela UNISAL de São Paulo (2013) e mestrado em Teologia pela Pontifícia Universidade Católica do Paraná (2018). Já exerceu o cargo de coordenador do Núcleo de Pastoral da Educação dos Oblatos de São José no Brasil. Atualmente é diretor geral da Faculdade Padre João Bagozzi e vice-diretor geral do Colégio Padre João Bagozzi Tem experiência na área de Educação, com ênfase em Pastoral Escolar, atuando principalmente nos seguintes temas: educação, pastoral da educação, pastoral e religião e gestão de instituições confessionais.
} 


\section{INTRODUÇÃO}

São José Marello, fundador da Congregação dos Oblatos de São José, dizia aos pais que era necessário "educar a mente e o coração" dos seus filhos (SANTIAGO E MIGLIETA, 2011 , 8). Sua paixão pelos jovens era objeto principal do seu apostolado, fruto de um contexto social, e um apelo temporal dos chamados "santos piemonteses" " que tinham um olhar voltado para a juventude de seu tempo.

O artigo 65 das Constituições dos Oblatos de São José (1988) diz que "a Congregação caminha nos caminhos de Deus e nas diretrizes traçadas pelo fundador quando consegue preparar membros capazes de animar e educar a juventude" (COSJ - CONSTITUIÇÕES DOS OBLATOS DE SÃO JOSÉ, 1988, art. 65).

Grande imitador de São José, pai-educador de Jesus, o fundador quis que seus oblatos fossem também fiéis no desejo de "cuidar dos interesses de Jesus”, assim como fez São José. Era sua convicção que o segredo da evangelização do mundo estava na formação integral da juventude.

O que caracteriza o modelo de educar dos Oblatos de São José, por inspiração de seu fundador São José Marello e por meio da experiência da educação dos primeiros oblatos no Brasil? Esse questionamento evoca um aspecto importante e fundamental, pois o desejo de São José Marello era educar a juventude na sua integralidade. José Marello dizia: "É preciso educar os jovens à firmeza nos propósitos, à fidelidade ao compromisso e ao espírito de luta" (SANTIAGO E MIGLIETA, 2011, 10).

Por isso, levanta-se como hipótese a possibilidade de observar se este desejo de São José Marello se tornou, de fato, um carisma empregado nos serviços educacionais e pastorais, gerenciados por aqueles que dele herdaram seu legado.

O pensamento de São José Marello anuncia um entendimento motriz para a realização desta pesquisa, ao inspirar os oblatos sobre o sentido da educação. Assim, percebe-se o papel da Pastoral Escolar como fomentadora dos valores josefinos-marellianos e molas propulsoras que ajudam as crianças, jovens, adolescentes e toda a comunidade educativa, a serem "verdadeiros cristãos e cidadãos virtuosos" (SANTIAGO E MIGLIETA, 2011,17).

Como objetivo norteador desta pesquisa, definiu-se identificar o modelo ou "jeito de educar" ${ }^{3}$. dos Oblatos de São José, por inspiração de seu fundador São José Marello e por meio

\footnotetext{
${ }^{2}$ Santos Piemonteses: santos nascidos na região do Piemonte, Itália, entre os séculos XVIII e XIX, que tiveram grande apelo pelo cuidado com a juventude (JOÃO PAULO II,1982).

${ }^{3}$ Emprega-se o termo "jeito de educar" quando se refere aos ensinamentos de São José Marello, devido ao fato de que o seu uso se tornou comum entre a comunidade Oblata, como um costume ao se referir às suas 
da experiência da educação dos primeiros oblatos no Brasil.

Foram utilizadas como fontes de pesquisa as realidades primárias da Congregação, ou seja, cartas fundacionais, constituições e regras, carta dos primeiros oblatos, bem como outros textos que fundamentaram a proposta pastoral e seus aspectos pedagógicos que dão sentido a todo processo ensino-aprendizagem, missão primária de qualquer escola.

Esta é uma pesquisa de abordagem qualitativa que consiste, geralmente, em uma forma de aprofundar uma unidade individual. Ele serve para responder a questionamentos que o pesquisador não tem muito controle sobre o fenômeno estudado (YIN, 2001,45).

Portanto, este artigo propõe uma reflexão sobre o jeito de educar dos Oblatos de São José, caracterizando o seu fundador, São José Marello, os respectivos fundamentos e pressupostos teóricos, relembrando enfim a experiência de educação dos primeiros oblatos.

Por isso, levanta-se como hipótese a possibilidade de observar se este desejo de São José Marello se tornou, de fato, um carisma empregado nos serviços educacionais e pastorais, gerenciados por aqueles que dele herdaram seu legado.

\section{O JEITO DE EDUCAR DOS OBLATOS DE SÃO JOSÉ}

Os princípios educacionais dos Oblatos de São José têm sua mística e fundamento naquilo que metaforicamente é chamado de "mística da casa de Nazaré" (COSJ,2017). Os Oblatos cultivam em suas instituições educacionais e sociais a ambiência da Casa de Nazaré, que possibilitou a educação de Jesus. Acredita-se que as escolas, faculdades e obras sociais podem ser "lugares da Casa de Nazaré", e, neles, germinar o espírito da família, no qual se sustenta a dimensão da fraternidade que tem caracterizado as instituições educativas.

A mística da Família de Nazaré provoca nos Oblatos um olhar especial para a missão que realizam todos educadores. Entendem-se como educadores todos os que participam do processo de educação integral dos jovens/alunos, entre eles professores, educadores sociais, diretores, coordenadores, técnicos administrativos e pedagógicos, agentes de pastoral, pais da família e os religiosos que acompanham todas as nossas escolas e obras sociais.

As instituições educativas, como "Casas-Escolas de Nazaré", sedimentadas na compreensão da religiosidade humana, precisam cultivar o sentido da "pertença" (olhar da gestão administrativa) e da "presença pedagógica e pastoral" (olhar dos professores e educadores).

inspirações educativas. 
Frente a esse objetivo, os Oblatos de São José buscam, em suas unidades educacionais, traduzir a mística da Casa da Família de Nazaré para os todos os processos administrativos e pedagógicos. Poder-se-ia dizer que a vida de José de Nazaré, que foi inspiração do projeto congregacional de José Marello, constitui hoje, para todas as províncias, o seu projeto educativo.

As escolas oblatas desejam vivenciar a "Casa de Nazaré", buscando ser "novos areópagos" (BÍBLIA, 1990, At17, 19ss) que evangelizam pelo conhecimento na relação educativa, que mostram "a Boa Nova" para a comunidade educativa.

\section{O FUNDADOR DOS OBLATOS DE SÃO JOSÉ: SÃO JOSÉ MARELLO}

Giuseppe Chiaffredo Steffano Marello, mais conhecido na Congregação dos Oblatos de São José, por ele fundada, como José Marello, nasceu no dia 26 de dezembro de 1844, em Turim, que na época era a capital da Itália. Era o primeiro filho de uma família com certa prosperidade econômica, visto que seu pai Vicente Marello se destacou por ser um comerciante de queijos. Sua mãe Ana Maria Viale era de família com bom poder aquisitivo, pois eram pessoas formadas na área médica e farmacêutica. Eles tiveram outro filho que foi chamado de Vitório Marello (DALMASO,1997).

Ao aprofundar um pouco o olhar sobre a vida de José Marello, será possível perceber que quase toda a sua existência aconteceu na segunda metade do século XIX, no Norte da Itália, lugar em que ocorriam, na época, diversas mudanças sociais, econômicas e religiosas, devido às várias revoluções que estavam acontecendo na Europa daquele tempo, bem como a luta pela unificação da Itália, processo que iria ocorrer até os anos de 1870. Dessa forma, é possível afirmar que ele conheceu e vivenciou todos esses movimentos. Segundo o entendimento de Forno $(2006,27)$ a vida de José Marello corta transversalmente um cinquentenário que exprimiu de modo excepcional muitas mudanças na história da Itália. De maneira especial, ocorreu a chamada década revolucionária dos anos 1840, o que levou nos anos seguintes a uma preparação e celebração do renascimento nacional e que acabou sendo bem-sucedida - a qual o próprio José Marello apoiava de maneira um pouco fervorosa em sua juventude.

Outro momento importante na vida de José Marello foi sua primeira passagem pelo seminário que se deu a partir de 31 de outubro de 1856. Nesse ambiente, ele se destacava pela sua inteligência e vida de piedade. Porém, a Itália vivia seu período de unificação e o governo havia tomado muitas medidas que acabaram afetando a vida da Igreja. Essas medidas anticlericais se deram especialmente entre os anos de 1850 e 1855. Uma delas foi a supressão 
quase total das ordens religiosas e o Estado tomando para si quase que todos os bens eclesiásticos. Todos esses fatores acabaram por afetar muito a vida religiosa no biênio de1856 a 1857 (FORNO, 2006,27).

Foi numa das fases mais importante da sua vida que ele vivenciou essas mudanças, ou seja, desde a infância até sua juventude. Foi nesse período que ele acabou sentindo os maiores impactos das mudanças que ocorreram ao seu entorno. Isso acabou de certa forma, afetando toda a sua vida seguinte, pois seu processo de formação e a busca de afirmação enquanto ser social, intelectual, profissional e, inclusive, espiritual sofreram muitas influências, seja do meio político quanto religioso. Foi também nesse momento da sua vida que ele passou pelo processo de educação formal. O maior momento da experiência educacional dele aconteceu nesse período 'conturbado' da história da Itália e, de maneira geral, em toda a Europa, pois, como sabemos, era um período de efervescência de muitas ideias que mexiam com a vida do povo, com a classe política, com a produção econômica e com a forma de educar e entender a educação. Escrevendo sobre esse período de estudo do José Marello, e de maneira especial sobre a escola em que estava inserido, Dalmaso $(1998,7)$ afirma que:

[...] a escola que ele frequentava naquele período era uma importação dos modelos escolares do norte da Europa, onde o ambiente protestante liberal havia substituído os modelos de escola clássica e humanística por aqueles de caráter técnico e econômico para preparar os jovens para o mundo industrial que estava nascendo naqueles anos.

A Itália dessa época tentava se afirmar as suas bases políticas. Uma das maneiras de infundir as novas ideias propagadas pelo estado foi por meio do processo educativo. Como se sabe, por meio da educação tem-se a possibilidade de transmitir um ideal ou algum tipo de interesse, principalmente aqueles que dizem respeito às necessidades do Estado. Ao comentar a esse respeito, Dalmaso $(1997,29)$ argumenta que com a lei de Boun compagni, que foi promulgada no ano de 1848, o Estado teve a intenção de regulamentar pela primeira vez a escola pública em todo o Piemonte, ou seja, no norte da Itália. Porém, a partir do ano de 1859, com a lei Casati, surgiu a primeira regulação sobre a instrução na escola pública. A intenção primeira era tirar das mãos da Igreja o processo educativo e transformar em instrução secular, a fim de formar novos cidadãos que pudessem atuar no estado liberal.

Esse processo perpassa toda a formação escolar de Marello. Talvez essas experiências importantes que marcaram sua história, fizeram com que ele tivesse a oportunidade de olhar o mundo e a sua realidade numa outra perspectiva. Como se sabe, todas as mudanças sociais, os movimentos políticos, questões econômicas e religiosas, de certa forma, acabam influenciando e possibilitando todo um conjunto de valores sobre as pessoas, além de trazerem coisas que 
podem ser categorizadas como positivas ou negativas. Na vida de Marello, isso não foi diferente. Quando se leem suas cartas juvenis, é possível observar, em várias delas, comentários a respeito daquilo que ele estava vivendo, além da sua preocupação com o momento histórico da sua pátria. É notável também que em outros seus escritos ele exponha suas preocupações com relação ao que acontecia com a Igreja e com a vida eclesial. Olhando assim, é possível verificar que ele era uma pessoa que compreendia as mudanças daquele momento.

Mas não foi só o ambiente em que Marello estava inserido que o formou. Pode-se observar que, segundo seus biógrafos, ele era uma pessoa privilegiada. Em alguns estudos que foram feitos todos afirmam que ele era brilhante na vida escolar, um exímio leitor, com grande capacidade para escrever e expor suas ideias, observador atento da realidade, esforçado nas suas tarefas e com visão de futuro. Num texto sobre seu retrato físico e espiritual, Pasetti $(2010,5)$ escreve:

[...] de inteligência pronta, saía-se muito bem nas matérias literárias: em 1860 uma redação sua sobre Vitório Alfieri, preparada por ele a um de seus amigos, obteve o primeiro lugar, mas ele não permitiu que soubessem o seu nome. Porém, saía-se melhor ainda nas ciências exatas.

Um momento que irá marcar a vida de José Marello será o ano de 1859, pois especificamente no dia 26 de abril tem início a guerra de Unificação da Itália. Durante os conflitos, os seminários acabaram se tornando quartéis para abrigar os soldados. Com José Marello não foi diferente, somente que o local onde ele estava acabou sendo ocupado um mês antes do início da guerra. Dessa forma muitos seminaristas acabaram tendo que deixar seus estudos e voltar para a casa de seus pais e outros foram acolhidos por famílias da cidade a fim de dar continuidade a seu processo de formação. Nesse período José Marello termina o ano escolástico na qual estudou retórica, mas começa a viver suas primeiras dificuldades devido a todas as mudanças que ocorreram naquele ano (DALMASO, 1997, 95-98).

Como parte obrigatória na formação de um seminarista, no ano de 1860, José Marello começou a estudar Filosofia. Como estudante, ele enfrenta as dificuldades que são normais para um jovem que está iniciando um curso superior. No entanto, no ano de 1861 e 1862 ele conclui o segundo ano de Filosofia. Foi nesse mesmo período que a Itália termina seu processo de unificação. Com isso, as ideias políticas de um estado liberal fizeram com que a Igreja acabasse sofrendo fortes pressões, sendo que muitos religiosos acabaram passando por acusações devido a diferenças entre o clero e o pensamento dominante propagado pela classe dominante e, no meio político, eram exaltadas as figuras de Vittorio Emanuelle II, Camillo Benso (Conde descavou), Giuseppe Mazzini e Giuseppe Garibaldi. Todos esses movimentos que mexeram 
com a vida social e eclesial da Itália, fez com que o jovem José Marello acabasse sentindo as mudanças no final do segundo ano de Filosofia. Achou melhor deixar o seminário para se tornar um bom leigo a fim de responder às necessidades da Itália (DALMASO, 1997, 135 -145).

Após deixar o seminário e por estar vivendo envolto a todas as mudanças que ocorriam no território italiano, José Marello assume seus sentimentos patrióticos e ao final do ano de 1862 ele parte para Turim com o objetivo de estudar no Colégio Técnico Comercial para dar início ao curso de comércio e para se dedicar à engenharia. Segundo Pasetti $(2010,5)$, nesse período teve uma vida muito ativa, tanto que "exerceu por cerca de um ano e meio a profissão de projetista e ainda conservava tempo de estudos para fazer o desenho de um desvio na estrada entre Govone e San Martinho Alfieri”. Esse desvio acabou sendo realizado anos mais tarde.

É importante ressaltar que nesse período, José Marello tinha certa admiração por Vittorio Alfieri, pensador que escreveu diversas obras e tinha consciência das necessidades da Itália e, mesmo que contrário às ideias do absolutismo, acabou se desiludindo com os excessos da Revolução Francesa. Apesar de ter mudado de ambiente e passado a estudar outros cursos, ainda se dedicava à leitura de diversas obras literárias e confrontava com a realidade italiana. Percebendo os momentos de dificuldades da Itália e dos abusos ocorridos no campo político, ele acabou se desiludindo com o pensamento de Vittorio Afieri, tanto que mais tarde acabou dizendo que não passava de pura ilusão. Mesmo diante de algumas desilusões, continuava seus estudos com a pretensão de se tornar um cidadão bem-sucedido (DALMASO, 1997,147-162).

No ano de 1863, escreveu algumas cartas a seus antigos amigos de seminário, colocando seu pensamento a respeito das novidades que estava vivenciando na capital italiana e, ao mesmo tempo, demonstrando-se preocupado com a situação que a Igreja estava passando. Nesse mesmo ano viu-se totalmente doente, pois havia contraído febre Tifoide. Essa foi uma experiência muito difícil e dolorosa que o fez repensar toda a sua vida naquele momento. Mais tarde testemunhou que foi curado pela intercessão da Virgem Santíssima, da qual era muito devoto. A partir dessa experiência de doença, decidiu retornar ao seminário para continuar seus estudos a fim de se tornar sacerdote. E assim o fez em fevereiro de 1864, quando retornou para Asti (DALMASO, 1997, 165-177).

A partir do ano de 1864, inicia os estudos em teologia e a se dedica cada vez mais na preparação para o sacerdócio. O que mais chama atenção sobre seus estudos são suas leituras e reflexões de uma grande lista de autores que acabaram influenciando seu pensamento, como, por exemplo, Pasetti $(2010,5)$ : 
que fazia... Leu com interesse o 'Telémeco' de Fenelon, os 'Mártires do Cristianismo' de Chateaubriand, os 'Sermões' de Massilon, os 'Pensamentos' de Pascal, 'Os Noivos' de Alexandre Mazoni, os livros de Gioberti e os de Balbo, as 'Confissões' de Santo Agostinho, a vida de Santa Margarida Alacoque. Sempre a partir dos escritos, conhecemos as seguintes obras por ele lidas ou citadas durante o período sacerdotal e episcopal: A 'SummaTheológica' de Santo Tomas de Aquino, a 'Regra' de São Bento, as 'Homilías' de São João Crisóstomo, a 'Filotéia' e os 'Colóquios espirituais' de São Francisco de Sales, as obras de Santa Tereza e São João da Cruz, o 'Maná da alma' de Segneri, 'O Combate Espiritual' de Scupoli, 'O grande meio da oração e Prática de amar Jesus Cristo' de Santo Afonso, as 'Máximas espirituais' de Rosmini, as 'Conferências espirituais de Notre Dame' de Lacordaire e as 'Conferências espirituais' de Pe. Faber, o 'Tratado da verdadeira devoção' de Montfort, a vida de São Jerônimo de Bougaurd, a 'Vida de São Carlos' de Sylvain, o 'Dicionário Histórico' de Moroni; e ainda a 'Imitação de Cristo' que ele carregava sempre consigo.

Desse seu empenho nos estudos, escreveu ao seu amigo Rossetti, no final do ano de 1866, afirmando que já havia recolhido nos três últimos anos um grande número de materiais e escritos pessoais em que examinava as chagas da sociedade italiana daquela época, a fim de elaborar um livro. Essa obra provavelmente seria de caráter ético-social. Porém esse trabalho nunca acabou sendo realizado, pois ele assumiu outros afazeres e nunca pode publicá-lo (BERTOLIN, 2008,16).

Olhando assim, parece que a sua formação trilhou o caminho sendo influenciado pela questão do ambiente em que estava inserido, bem como pela sua personalidade e inteligência. Mas lendo um pouco mais a sua biografia é possível observar que desde a sua infância, ainda na casa paterna, já havia uma grande preocupação com a boa formação. Escrevendo sobre os primeiros anos de escola e sobre a formação em sua família. Dalmaso (1997, 32-33) assim relata:

[...], por conseguinte, sem impedir o desenvolvimento futuro dos acontecimentos, é importante entender as duas linhas de ação e de formação que foram dadas na família Marello: uma primeira linha, digamos assim, José e Vittorio são inseridos na vida do país; uma segunda linha, que ocupará mais e mais o seu tempo para seguir o caminho humano, espiritual e religioso, em preparação para seu futuro vocacional, será todo fora do povoado de SanMartino.

Portanto, para tentar estabelecer um paralelo na vida de Marello, talvez seja oportuno olhar estes dois aspectos: uma pessoa de grande personalidade, inteligência, que teve uma boa formação desde os tempos da casa paterna e uma pessoa que viveu numa época de grandes movimentos promoveu re-olhar a história não como espectador, mas como protagonista.

Todo esse seu empenho e suas experiências no campo social, político e, principalmente espiritual, foi culminado no dia 19 de setembro de 1868. Nesse dia ele foi ordenado sacerdote pelo então bispo da diocese de Asti, dom Carlo Savio. A partir da sua ordenação sacerdotal ele 
assume como secretário do bispo e começa, ao mesmo tempo, a desempenhar seu trabalho tendo uma especial tendência para com a juventude, as crianças órfãs e a catequese. Enquanto secretário do bispo, José Marello teve a oportunidade de fazer algumas experiências que foram muito importantes para a sua vida futura. Nos meses de novembro de 1869 a agosto de 1870 participou do Concílio Vaticano I. Para ele foi um momento valioso, pois teve a oportunidade de acompanhar de perto as diversas discussões e decisões da fé católica, sobre o primado e infalibilidade do papa e, por fim, tratou de questões doutrinárias a fim de informar melhor sobre assuntos essenciais de fé. Desse momento, José Marello pode conhecer mais de perto os problemas que a Igreja enfrentava em todo o mundo (DALMASO, 1997,451-482).

Ainda como secretário, a partir do ano de 1871 passa a acompanhar seu bispo na visita pastoral que aconteceria em todas as paróquias da diocese de Asti. Nessas suas visitas ele pode conhecer melhor os problemas da Igreja local, ver mais de perto as dificuldades dos padres, pode ter contato com os operários, encontrou povo que estava reconstruindo suas vidas depois da guerra de unificação e, de modo especial, verificou os problemas enfrentados pela juventude. Tudo isso deu a José Marello uma enorme experiência e, ao mesmo tempo, motivou-o a desenvolver algo que pudesse ir ao encontro daqueles que mais necessitavam. Assim sendo, no ano de 1872 tem a ideia de fundar a Companhia de São José. Essa companhia assemelhava-se com as primeiras experiências de leigos que já haviam surgido na Itália. No entanto, no pensamento de José Marello seria uma "meia associação e uma meia confraria, com finalidades de promoção social, sobretudo entre os jovens e os mais necessitados” (DALMASO, 1998,33).

Essa sua primeira tentativa de fundar uma companhia não foi bem sucedida, pois pareceu ser uma novidade muito grande na cidade de Asti, que contava naquela época com apenas com duas obras sociais, a Obra Pia Mechelerio e o Asilo Cerrato. Nesse período, já havia superado os sonhos juvenis e suas decisões eram a cada dia mais elaboradas para que seus projetos pudessem alcançar os objetivos desejados. Assim, entre os anos de 1873 a 1878 aprofundou seu conhecimento sobre as diversas companhias e associações católicas que surgiam na Itália e também na Europa, em especial o trabalho desenvolvido por São João Bosco, em Turim. Além do mais, dedicou-se à recuperação do Asilo Cerrato que se encontrava com muitas dificuldades em sua manutenção e, ao mesmo tempo, acompanhou de perto e colaborou em todos os trabalhos da Obra Pia Michelerio. Todas essas experiências deram a José Marello a oportunidade de chegar em 1878 e fundar a Companhia de São José, que mais parte passou a ser chamada como Congregação dos Oblatos de São José (DALMASO, 1998,34-35). 
Michelerio a Companhia de São José. Esta companhia teve sua origem laical, mas também era enriquecida com as contribuições espirituais e religiosas feitas por José Marello. O grupo era composto de quatro pessoas sendo eles Giorgio Medico, Pietro Luigi Biamino, Giuseppe Luigi Rey e Vicenzo Franco. No início, seus primeiros trabalhos foram juntos aos órfãs e internos que estavam naquela instituição. Dessa forma, José Marello começava a formar um grupo que mais tarde pudesse atuar especialmente na educação e promoção da juventude (DALMASO, 1997, 646-648).

O grande intuito de José Marello era responder às necessidades do seu tempo. Ele não viveu num momento de facilidades, nem tampouco cheio de privilégios. Ele precisou encarar os problemas e ir ao encontro de alternativas para solucioná-los. Assim, tornou-se uma pessoa proativa que procurou fazer algo para responder aos problemas se sua época. De certa forma, todas essas preocupações faziam com que ele 'apostasse', ou melhor, acreditasse no ser humano. Isso tenta explicar um pouco sua vontade em fazer a caridade e, ao mesmo tempo, dar condições para que a pessoa pudesse viver com seus próprios esforços(DALMASO,1997, 52) é possível ser lido um testemunho do Padre Giovanni Battista Cortona, relatando que "nos 17 anos que convivi com a amável presença de José Marello, tive provas evidentes e constantes que ele tinha um coração sinceramente amante de todas as pessoas com as quais tinha que tratar". Esse talvez fosse o grande diferencial de Marello: querer o crescimento do ser humano.

\section{PEDAGOGIA MARELLIANA: UM JEITO DE EDUCAR A MENTE E O CORAÇÃO}

Em estudo inicial, intitulado Gênese da Pedagogia Marelliana (2013) ${ }^{4}$, Mario Guinzoni, religioso oblato, aponta algumas características e hipóteses da formação do pensamento de Marello. O autor destaca que Marello foi um homem estudioso que se esforçou em compreender o contexto social do seu tempo, fato que fica evidente nas suas cartas escritas aos seus amigos.

Marello, a partir da leitura de autores franceses, no contexto emergente de ideias socialistas e liberais, como: “As aventuras de Telêmaco" (PASETTI, 1979, C.4) do bispo François de Salignac de La Mothe (1651-1715); da leitura de Jules Michelet (1798-1874) (PASETTI, 1979, C.5) que lhe permitiu compreender criticamente a obra de Blaise Pascal (1623-1662) (PASETTI, 1979, C.6); e de autores como Chateaubriand, Manzoni e Balbo que lhe proporcionaram a visão de um apostolado católico-humanitário (DALMASO, 1997, 63).

Também seus conhecimentos sobre as experiências e diversas iniciativas pastorais educativo-sociais de santos como José Cafasso (1811-1860), João Bosco (1815-1888), José

\footnotetext{
${ }^{4}$ Artigo publicado no vol. 1, n. 1 da Revista Identidade Oblata, outubro de 2013. Disponívelem: <http://www.faculdadebagozzi.edu.br/portal/38-240-382/nipe-centro-de-memória-dos-oblatos-de-s-josepublicacoes $>$.
} 
Agustinho Bento Cottolengo (1986-1842), José Allamano (1851-1926), Leonardo Murialdo (1828-1900), entre outros, contribuíram na formação do pensamento de Marello a tendência de uma possível 'pedagogia humano-espiritual' como a chamou Guinzoni (2013). Isso levou a que Marello fizesse parte do grupo dos santos piemonteses chamados 'sociais', justamente pelo empenho em obras sócio humanitárias da caridade cristã (GUINZONI, 2013,79).

Em relação aos seus modelos espirituais, destacaram-se São Francisco de Sales (15671622) com o qual será comparado posteriormente e chamado de "o novo São Francisco de Sales" (DALMASO, 1997, 83), Bruno Pio Lanteri (1759-1830), Luigi Guala (1775-1848), Giuseppe Cafasso (1811-1860), São Alfonso Maria de Ligório (1696-1787), Santa Teresa de Ávila (1515-1582) e São Inácio de Loyola (1491-1546) que inculcaram em Marello sua sensibilidade apostólica para o social. Esta sensibilidade, segundo Guinzoni $(2013,65)$ constitui um dos motivos da fundação da COSJ e da criação de uma espiritualidade Josefina, da revitalização de uma casa de acolhida para a terceira idade de saúde crônica que estava fechando as portas, e que fez com que se dedicasse, junto a outros sacerdotes, à educação da juventude.

Finalmente, o pensamento pedagógico de Marello emerge do educador francês Felix Antoine Philibert Dupanloup (1802-1878), que se destacou pelo seu método catequético e sua concepção disciplinar para o ensino (C. 15) e da experiência socioeducativa de João Bosco no serviço aos jovens, pobres, nas escolas, institutos técnicos e profissionais, hospitais, dispensários, oratórios e paróquias. A este se lhe atribui à criação de um sistema de educação preventiva, com base numa relação afetiva e compassiva.

Com base nos apontamentos anteriores, percebe-se que o pensamento de Marello foi constituído por influência das ideias do humanismo francês, pelos modelos espirituais de caridade e do contato simbólico e concreto de experiências de educação social com diferentes sujeitos.

Marello não escreveu nenhum tratado sobre suas ideias pedagógicas que nos permitam a descrição específica do seu pensamento. Da sua produção escrita destacam-se as duas cartas pastorais: a quarta carta de 1892 sobre a instrução escolar e a educação dos jovens na família (SANTIAGO E MIGLIETA, 2011, 98) e a sexta carta de 1894 sobre o catecismo (SANTIAGO E MIGLIETA, 2011, 87), nas quais é possível evidenciar aspectos teórico- metodológicos sobre uma "instrução doméstica da juventude e da catequese" com forte ênfase social.

O apelo à educação religiosa, principalmente da catequese, é um aspecto forte na visão de Marello que se relaciona à compreensão de uma formação humana virtuosa, questão que fica clara na sua crítica a Jacques Rousseau e no realce da educação da pessoa de Jesus como modelo 
de vida. Marello aponta também o papel da família como diretriz e exemplo no processo de educação cristã dos jovens. Reconhece a família como responsável pela educação do jovem e a escola (educação para a cidadania) e a Igreja (catequese como processo de educação da fé) como colaboradoras nesse processo de formação. Entende a educação moral como uma educação do coração, uma educação para a sensibilidade social (DALMASO, 1979, 67-69).

Santiago e Miglieta $(2011,23)$ comentam que:

A educação do coração, introduzida pelo pedagogo suíço, Johann Heinrich Pestalozzi (1746-1827) que conhecia a natureza humana sujeita a instintos e paixões biológicas desordenadas, adquire em São José Marello o sentido mais profundo de formação da consciência. $\mathrm{O}$ coração indica a esfera afetiva que concerne aos sentimentos e à intencionalidade profunda, ou seja, àquela área onde são tomadas as decisões fundamentais sobre o próprio ser no mundo (GIUSEPPE DEMARCUS, 2011) .

Pestalozzi era assumidamente religioso e cristão. Tinha ideias antropológicas, usando duas expressões evangélicas: sentimentos de fé e de amor que há que cultivar na criança e que há que fundá-los na moralidade e na religiosidade (e também nos sentimentos das relações familiares). Com certa conexão à filosofia kantiana, Pestalozzi defende a concepção da religião que tem como função principal e até única ajudar a moralidade das pessoas e da humanidade, assegurando ao mundo um verdadeiro comportamento moral. Para Pestalozzi, a religião é muito mais que isto, já que, baseando-se na fé e no amor, procura uma fundamentação não somente natural e humana da boa conduta, senão que leva a um pensar, sentir e obrar cristãos ${ }^{6}$.

"Educar o coração" é uma diretriz pedagógica de todos os santos piemonteses que trabalharam no meio dos jovens e no social. Marello é influenciado pelo método de catequese da escola francesa, especificamente de Saint-Sulpice, e pelos escritos de Dupanloup, que lhe motivarão ao reconhecimento do caráter formativo da catequese:

Ao aperfeiçoamento moral do homem, não basta o cultivo da mente sem a educação do coração: ou melhor dizendo, a instrução por si só e sem o acompanhamento da religião não pode dar luz verdadeira ao intelecto, nem mover eficazmente à vontade para o bem, donde, para o progresso moral é necessário que o homem conheça o fim pelo qual se move, o fim a que tende, o exemplo que lhe deve servir de norma, a força que deve prestar-lhe a ajuda necessária e oportuna" (MARELLO, 1894, S.82. In: SANTIAGO E MIGLIETA, 2011, 90).

Esta citação ressalta que o coração não pode ser educado a seguir Cristo, se não através de outro coração educado assim, já iluminado e movido por Cristo. Este chamado aos educadores e catequistas é crucial no entendimento da missão da educação do coração: "os mansos possuem antes de tudo o próprio coração, e depois também o coração daqueles que os

\footnotetext{
5 SANTIAGO, A.; MIGLIETA, G. (coeditores). São José Marello - Um coração para os jovens (JOSEPH), 2011,91 .

${ }^{6}$ PESTALOZZI, J. El canto del cisne. Barcelona: Laertes, 2003. 
circundam, os quais não podem deixar de admirá-los, amá-los, agradá-los e servi-los" (S.284). A educação do coração é pelo exemplo, pela prática das virtudes, pelo amor percebido e sentido pelo educando(amorosidade).

Guinzoni (2013, 59-60) sintetiza a mensagem educativa das duas cartas pastorais, e aponta aspectos importantes, que marcam o pensamento pedagógico de José Marello:

\begin{abstract}
As duas cartas pastorais sobre a instrução dos jovens e catecismo, Marello, falando da "educação do coração" diz claramente como todo ato educativo, no nível humano e religioso, é tal se permeado de caridade e de amor, pois, como diz Dom Bosco, a "educação é uma coisa de coração". O estilo de "caridade" se traduz em amor sobrenatural, que é paixão por Deus e pelos seus filhos, de forma especial os "pequenos", ou seja, um estilo relacional feito de presença humana maternal e paternal, fraterna, de diálogo, de compreensão profunda pelo qual o educador, sobretudo se pai-mãe e sacerdote, professor, vive, dentro das possibilidades da vida. A vida dos filhos, dos jovens e os ama, se identifica com o que eles amam. Osistema preventivo de Dom Bosco é a caridade em ação" (cfr. 1 Cor13,4-7). ${ }^{7}$
\end{abstract}

Partindo de Deus, da sua palavra, do catecismo, a educação deve falar principalmente ao coração da juventude e em qualquer lugar sempre. Também na disciplina deve dominar o amor. Também a correção e o castigo devem ser permeados de amor. O sentirem-se amados gera confiança, familiaridade, deixa livre interiormente, cria espírito de família, e o amor assim manifestado e percebido torna-se ainda válido para o mesmo educador. $\mathrm{O}$ amor cristão é o fundamento de todo relacionamento educativo, formativo e favorece a assimilação dos valores humanos e religiosos. (GUINZONI, 2013,59-60)

No pensamento pedagógico de Marello, a educação é compreendida como um caminho para a completa atualização da potencialidade humana. Nesta perspectiva, entende a pedagogia humanista com base na antropologia cristã que anela a formação integral do homem para ser um “ótimo cidadão e um cristão virtuoso", isto é, um ser histórico-cultural e aberto à transcendência.

\title{
5. A EXPERIÊNCIA DE EDUCAÇÃO DOS PRIMEIROS OBLATOS
}

O apostolado social de Marello situa-se no contexto da segunda metade do século XIX na Itália, que na época vivia um período de fragmentação política produto de guerras civis e regimes de dominação estrangeira unido a manifestações de movimentos sociais, sindicais e revolucionários da classe trabalhadora. O cenário italiano confluía no embate de problemas sociais, políticos, filosóficos e teológicos que se imbricavam nas correntes racionalistas e positivistas que prometiam o progresso ilimitado da ciência, em detrimento da visão teocêntrica.

\footnotetext{
${ }^{7}$ GUINZONI, M. Gênesis da Pedagogia Marelliana. In: Revista Identidade Oblata, v. 1, n. 1, Curitiba, 2013. REVISTARELEGENSTHRÉSKEIA - 2019 - UFPR
} 
O trabalho social de José Marello, desde 1868, direcionou-se à educação catequética e à ajuda na implantação de "pequenas bibliotecas paroquiais, de salas de leitura, organização de encontros de formação para a juventude e para os adultos” (RISSO, 2001, 105). Essa especificidade do trabalho pastoral de Marello com a juventude surge da realidade da juventude italiana da época que enfrentava um contexto de tensões ideológicas, de violência e de falta de sentido de vida. Isso fica evidente na Carta 28 de 1869, quando Marello dizia: "Trabalha, trabalha para melhorar a juventude; também o pouco é algo e impedir o mal em nossos dias já é um grande bem" (DALMASO, 1979,97)

Destacou-se na época o surgimento da Società della Gioventù Cattolica em 1867, na qual Marello participou em conjunto com o bispo Dom Sávio na promoção de instituições sociais e sociedades católicas em Turim e Piemonte (RISSO, 2001).

Bertolin $(2000,35)$ relata que Marello como sacerdote, tinha uma grande vontade de trabalhar no meio do povo, particularmente com a juventude em seu coração, cheio de ideias religiosas e sociais, estava inclinado para os mais pobres e desfavorecidos. Sobre isso, Risso $(2001,106)$ ressalta que "pelos jovens ele rezava, trabalhava e recomendava a ação: isto é, o catecismo, a instrução religiosa, a educação cristã".

Essas percepções se verificam nas cartas escritas por Marello ao final da década de 1860. Na sua carta 25 (janeiro, 1869) descreve a necessidade de leitura do contexto europeu e reforça as palavras de Guizot: "L'Europa soffre per difetto di fede di speranza e di carità", destacando a sua preocupação pelas transformações sociais e de afirmação dos princípios do Cristianismo.

No texto da carta 29, escrita por Marello em Asti no 20 de fevereiro de 1869, reforçase este apelo aos fatos da realidade e reafirma a importância do trabalho com a juventude:

\footnotetext{
"Ah! Pobre juventude, tão abandonada e esquecida; pobre geração nova, deixada sobremodo à própria sorte e ainda muitíssimo caluniada ou, pelo menos, duramente julgada em suas leviandades e em sua generosidade mal contida, naquela necessidade de ação mal desenvolvida, de afetos mal orientados, pelos quais, sem culpa totalmente dela, se afastado caminho reto! Pobre juventude! Rezemos mui particularmente por ela" (PASETTI, 1979,37).
}

O texto de Marello deixa em evidência a necessidade de políticas públicas para a juventude da época, principalmente de políticas educacionais. Também é importante destacar que Marello assiste a Obra Pia Micheleiro (1860) dirigida pelo cônego Giovanni Cerruti, destinada aos órfãos e abandonados e também o Hospício dos crônicos, fundado em 1874 por Francesco Cerrato, com apoio de Dom Sávio. Estas realidades foram exemplos para o projeto 
social do Marello. Num de seus escritos Marello (25 de outubro de 1872) reconhecia o trabalho de Cerruti no antigo Mosteiro das Irmãs de Santa Chiara dizendo: "Acolha a mim e a alguns dos meus amigos num mesmo espírito de união sobre os auspícios de São José para servir aos interesses de Jesus na nova Igreja" (RISSO, 2001,130).

Marello concentrou as suas ações socioeducativas na casa de acolhida Santa Chiaraem Asti, Itália, na qual se destinou à acolhida da terceira idade e a um orfanato para adolescentes e jovens dedicado à catequese nas paróquias e à formação escolar desses.

Tais iniciativas seriam posteriormente institucionalizadas por Marello no dia 14 de março de 1878 mediante a fundação da Pia Associação Oblatos de São José.

Segundo Bertolin $(2009,76)$ existem três razões fundamentais para a fundação da Congregação dos Oblatos de São José: 1. Espiritual-pessoal, do Marello como religioso; 2. Teológica, pela revalorização da prática dos conselhos evangélicos; e 3. Pastoral, pela situação de formação da juventude e dos mais necessitados.

Paralelamente, movia-se pelas linhas do serviço aos jovens, no "Coleginho" com os órfãos e nas escolas com a catequese; do serviço pastoral nas paróquias, na ajuda à diocese e do serviço aos mais pobres, no Hospício e nas iniciativas que posteriormente nasceriam (RISSI, 2001, 45).

Em 1882, Cerrato cedia aos cônegos Sardi, pároco da catedral e a Marello, chanceler da Cúria, o Hospício dos Crônicos. No mesmo ano, Marello e Sardi adquiriam o asilo Cerrato que abrigava homens e mulheres abandonados com deficiências físicas ou mentais. Bertolin (2009, 26) destaca que "o total de internados desde o ano de 1901 até 1910 foi de 178 pessoas, das quais a metade era composta de órfãos", fato que levaria os Oblatos a serem conhecidos como “fratini dell' Ospizio di Santa Chiara". Um ano mais tarde, o antigo Mosteiro de Santa Chiara foi vendido à Igreja de Asti e seriam assumidos por Dom Bertagna, os cônegos Marello e Sardi e o padre Bellino. Em Santa Chiara, Marello iniciou um trabalho catequético com um grupo de cem jovens operários (BERTOLIN, 2009, 67). Tal evento motivou que Marello levasse os religiosos para Santa Chiara $^{8}$ os quais ainda se encontravam na Obra Micheleiro, e consequentemente, que os Irmãos de São José se tornassem cada vez mais autônomos (RISSO, 2001,58).

Sobre o contexto do apostolado social dos primeiros oblatos, é notável o protagonismo

\footnotetext{
${ }^{8}$ Bertolin $(2009,129)$ relata que, "Santa Chiara antes de Marello falecer estudantes, 10 irmãos coadjutores e 4 sacerdotes, formava uma família de 214 pessoas. No Colégio Frinco estavam 46 estudantes, incluindo 5 irmãos coadjutores, 3 sacerdotes e 7 funcionários, somando um total de 61 pessoas". O Castelo de Frinco foi adquirido o dia 30 de maio de 1893, tendo como titulares os padres Enrico Caradino, Giovanni Cortona, Giorgio Medico e Vincenzo Baratta. O mesmo disponha de 90 quartos e serviu para o funcionamento do noviciado.
} 
de diversos fundadores de congregações religiosas como João Bosco, Francisco Faà de Bruno, Leonardo Murialdo e de José Marello, que se preocuparam pela situação social de crianças, adolescentes e jovens da época visando à promoção da dignidade humana (GALLIANO, 1993,34).

Durante o período episcopal de Marello, em março de 1895 foi fundado na Catedral de Asti, o Oratório Juvenil São João, que mais tarde passaria a chamar-se São Luiz. O oratório acolhia crianças, adolescentes e jovens oferecendo a catequese e programas assistenciais. Devido ao crescimento e falta de infraestrutura, o oratório foi transferido em 1905 para Fulgor, onde se constituiu como uma espécie de Casa Recreativa com o lema "Deus, Família e Pátria". Nela aconteciam cursos de cultura religiosa e se reuniam grupos de catequistas católicos jovens, equipe de ginástica e de uma banda musical. Bertolin $(2009,34)$ ressalta que entre 1905 e 1907 o Oratório São José teve um saliente crescimento, passando de 193 para 378 jovens que participavam das atividades.

Em janeiro de 1903 foi inaugurada a Casa da Providência que se dedicou ao trabalho com jovens que aprendiam técnicas de sapataria, carpintaria, alfaiataria e tipografia. Esta casa, a Opera Pia Micheleiro, foi um orfanato para jovens artesãos de Asti dirigido por um sacerdote e por dois clérigos assistentes. Posteriormente, na mesma Casa da Providência seria implantado um espaço para o cuidado com a terceira idade. Em 1904, a Congregação dos Oblatos de São José adquiriu a Casa da Imaculada, na qual passou a funcionar o internato Marello, que constituiria a primeira obra oblata fora do território de Piamonte (BERTOLIN, 2009,56).

Sendo assim, os oblatos no início do século XX contavam com oito casas destinadas ao trabalho social: a Casa de Santa Chiara em Asti desde 1884 (probandato, colégio de internato, orfanato masculino e asilo); a Opera Pia Micheleiro desde 1901 (orfanato para jovens artesãos); o Santuário da Moretta em Alba desde 1901 (serviços paroquiais e oratório); o Santuário da Mercê em Asti desde 1903 (escola diurna e noturna para os habitantes e oratório); o Santuário de Nossa Senhora da Providência em Cussiano di Fonssano desde 1903 (escola e trabalhos litúrgicos); a Casa da Providência em Pontremoli desde 1904 (serviços paroquiais e oratório); e uma Casa em Canelli desde 1904 (oratório) (BERTOLIN, 2009, 78).

Tal panorama do apostolado dos Oblatos não foi uma particularidade unicamente da COSJ, mas constituiu uma realidade da Itália desde início do século XX. Bertolin $(2009,20)$ ressalta que "começaram a surgir iniciativas válidas no campo religioso e social, tais como fundações de círculos, comitês, oratórios, sociedades esportivas e atividades caritativas com a multiplicação de orfanatos e assistência aos imigrantes". Na época, surgiram a Associação 
Nacional para os Missionários Italianos no exterior sustentada pelo governo italiano, as Semanas Sociais, o Movimento Missionário, a Federação das Associações Esportivas Católicas, movimentos de difusão do catecismo e iniciativas missionárias populares, em cuja participação, o padre Cortona e o padre Baratta se destacaram. Os Oblatos foram protagonistas do apostolado social, serviam diariamente em institutos, hospitais, escolas, conventos femininos, paróquias da cidade e capelas rurais.

\section{CONSIDERAÇÕESFINAIS}

Nesta pesquisa, pode-se perceber que o desejo de José Marello de cuidar dos interesses Jesus, no modo de São José, pai e educador de Jesus, aconteceu ao longo da história. Inicialmente com o próprio Marello, que viveu claramente esta máxima. Depois, na vivência fiel dos primeiros oblatos ao longo da história e, por último, esta pesquisa levou-nos à comprovação deste fato também na história dos oblatos no Brasil que, com bravura e ousadia, viveram esses ensinamentos com profundidade.

Não há dúvidas de que contexto social em que viveu José Marello, seu modo de vida, abriu-lhe horizontes para que a sua forma de evangelização fosse fecunda e inspirasse também os oblatos que o sucederam a viver toda a herança por ele deixada. Essa herança foi percebida em seus ensinamentos, enquanto exerceu ativamente sua obra, mas também através das suas cartas que documentaram o seu período episcopal.

Procurando afastamento de uma visão romantizada, é possível verificar a atualidade do carisma de São José Marello e afirmar que esse carisma permanece vivo na mente, nas obras e no coração dos oblatos. Consequentemente, nas ações pastorais é possível tocar a vida de cada jovem e de suas famílias.

A partir da história dos Oblatos, desde a sua proposta de fundação até o seu desenvolvimento, procurou-se verificar a identidade carismática, a pedagogia marelliana, para uma formação humana virtuosa. Assim, aponta-se alguns aspectos que revelam a atualidade do carisma de São José Marello

a) há nos oblatos uma preocupação pela educação social, a partir de uma leitura das necessidades sociais do contexto atual que orienta o seu agir socioeducativo;

b) os oblatos à luz da espiritualidade do fundador consideram os espaços socioeducativos como as "novas Igrejas" para o exercício dos seus apostolados (sensibilidade apostólica para o social);

c) o trabalho social dos oblatos sempre esteve orientado pelas ideias pedagógicas do 
humanismo cristão, na educação moral e catequética, e para o exercício da cidadania e para o trabalho;

d) há nos oblatos um reconhecimento da família e dos educadores como responsáveis pela educação da mente e do coração da juventude.

Educar a mente e o coração é, talvez, um dos pressupostos máximos do "jeito de educar" para São José Marello. Esse desejo, fortemente presente nos seus esforços, motivou a realização desta pesquisa, no intuito de entender como estes pressupostos se revelam nas atividades pastorais nas instituições educacionais oblatas brasileiras.

Neste percurso, verificou-se a atualidade do carisma de São José Marello. Passado mais de um século, e sem deixar de considerar as diferenças especialmente culturais e sociais deste novo tempo, entende-se que os seus ensinamentos fundamentais, ou seja, a sua essência, continua viva, mesmo que em nova forma, própria dos novos processos e técnicas presentes no ambiente educacional.

\section{REFERÊNCIAS}

BERTOLIN, J. Breve história da Congregação e da Província Brasileira dos Oblatos de São José. Curitiba: OSJ, 1994.

, J. Dom José Marello: um santo para ser amado e venerado. Curitiba: BAGOZZI, 2000.

, J. São José Marello - focado em algumas particularidades de sua vida. Apucarana: Centro de Espiritualidade Josefino-Marelliana, 2008.

, J. História da Congregação dos Oblatos de São José 1878-1895. Material digitalizado e arquivado nos documentos da Pastoral da Educação Universitária da Faculdade Padre João Bagozzi, 2009.

2017.

J. São José, Aquele que exprimiu as perfeições de Deus na terra. Apucarana: Editora Graf Art,

, J. Uma abordagem histórica da Congregação dos Oblatos de São José no Brasil - 1919 2009. Organizado por Fernando Klein e publicado em 2009 em comemoração aos 90 anos de presença da COSJ no Brasil.

BÍBLIA SAGRADA. N. T. Atos 17, 19. In BÍBLIA Sagrada: Edição Pastoral. São. Paulo: Paulus, 1990.

. N. T. Lucas 2, 52. In BíBLIA Sagrada: Edição Pastoral. São. Paulo: Paulus, 1990.

BRASIL. LDB. Lei das Diretrizes e Bases, art. 02. LEI N 9.394, DE $20 \quad$ DE $\quad$ DEZEMBRO

DE 1996. Disponível em http://www.planalto.gov.br/ccivil 03/leis/19394.htm.

Extraído em15.dez.17. 
CORTONA, J. A caridade de Dom Marello. Trad. José Antonio Bartolin. In: Estudos Marellianos. $2^{\mathrm{a}}$ ed. Curitiba: 2010.

CONGREGAÇÃO DOS OBLATOS DE SÃO JOSÉ: Casa Escola de Nazaré: o jeito josefinoMarelliano de Educar, 2017.

: Constituições dos Oblatos de São José. Roma, 1988. art. 65.

: Documento Passo a Passo: um olhar para os jovens, 2005.

. Estudos Marellianos. 2010.

DALMASO, S (org.). Le LetteredelVenerabile Giuseppe Marello. Tipografia San Giuseppe, Asti, 1979.

, S. Biografia del Beato Giuseppe Marello fondatore degli Oblati de San Giuseppe e vescovo di Acqui. Volume Primo. Roma: Libreria Editrice Vaticana, 1997.

S. O Bem-Aventurado José Marello: reflexões sobre a biografia do bem-aventurado José Marello. Curitiba, 1998.

CONGREGAÇÃO PARA O CLERO. Diretório Geral para a Catequese, 1997. Disponível em http://www.vatican.va/roman_curia/congregations/cclergy/documents/rc_con_ ccatheduc_doc_17041998_directory-for-catechesis_po.html.Acessoem28.nov.17.

FORNO, M. San Giuseppe Marello e il suo tempo. In: Marellianum - Storia e Spiritualità di San Giuseppe Marello e dellaCongregazionedegliOblati di San Giuseppe. Anno XIV, n 58. Roma: 2006.

GALLIANO, J. Un santo para nuestros tempos: beato José Marello. Oblatos de San José, Perú,1993.

GUINZONI, M. Gênesis da Pedagogia Marelliana. In: Revista Identidade Oblata, v. 1, n. 1, Curitiba, 2013.

PASETTI, M. José Marello retrato físico e espiritual - estilo de vida. Trad. Álvaro de Oliveira. In: Estudos Marellianos. $2^{\mathrm{a}}$ ed. Curitiba: 2010.

, M. Lettere del Venerábile Giuseppe Marello. Asti, 1979. In: Cartas do Período Sacerdotal. Ed. COSJ. Curitiba: 2007.

PESTALOZZI, J. El canto del cisne. Barcelona: Laertes, 2003.

SANTIAGO; A. MIGLIETA, G. São José Marello: um coração para os jovens. Cartas de um bispo a mães e pais, catequistas e professores. Ed. OSJ, Curitiba:2011.

YIN, Robert K. Estudo de caso - planejamento e métodos. (2Ed.). Porto Alegre: Bookman. 2001. 